\title{
Perfis clínico e hematológico de camundongos submetidos ao envenenamento escorpiônico experimental por Tityus fasciolatus
}

\author{
[Hematological and clinical profiles of mice submitted to experimental \\ poisoning with Tityus fasciolatus venom] \\ P.T.C. Guimarães, M.C.L. Pinto, M.M. Melo* \\ Departamento de Clínica e Cirurgia Veterinárias - Escola de Veterinária - UFMG \\ Av. Antônio Carlos 6627 \\ Caixa Postal 567, Campus da UFMG \\ 30123-970 - Belo Horizonte, MG
}

\begin{abstract}
RESUMO
Estudou-se o quadro clínico do veneno decorrente do envenenamento por Tityus fasciolatus e sua ação refletida nos componentes hematológicos no modelo murino. Para o estudo do perfil hematológico, foram utilizados 54 camundongos Swiss CF1, machos, com 30g, distribuídos em três grupos (G) (n=18) inoculados via subcutânea com: $50 \mu \mathrm{L}$ de PBS (G1); $24 \mu \mathrm{g}$ de veneno de T. fasciolatus (G2) e $8 \mu \mathrm{g}$ de veneno de T. serrulatus (G3). Cada grupo foi subdividido em três subgrupos $(\mathrm{n}=6)$ de acordo com o momento da coleta de sangue que foi estipulada em uma, oito e 24h após a inoculação do veneno, e foram realizados o hemograma e a dosagem de proteínas totais e fracionadas. $\mathrm{O}$ veneno de $T$. fasciolatus na dose de $24 \mu \mathrm{g}$ causou piloereção, comportamento nociceptivo, secreção nasal e oral acentuada, dispneia, prurido na face e reflexos exacerbados. No exame hematológico, foram observadas policitemia relativa e leucocitose com linfocitose.
\end{abstract}

Palavras-chave: escorpião, Tityus fasciolatus, hematologia, alterações clínicas, camundongo

\begin{abstract}
The aim of this study was to evaluate the clinical picture caused by Tityus fasciolatus and its action reflected in mouse blood profile. To study the blood profile, 54 Swiss CF1 mice, male, 30g, distributed into three groups $(G)(n=18)$ and inoculated subcutaneously with: 50 $\mu$ l PBS (G1), $24 \mu \mathrm{g}$ of venom of $\mathrm{T}$. fasciolatus (G2) and $8 \mu \mathrm{g}$ venom T. serrulatus (G3) were used. Each group was subdivided into three subgroups $(n=6)$ according to the time of blood collection that was set at $1 \mathrm{~h}, 8 \mathrm{~h}$ and $24 \mathrm{~h}$ after inoculation of the venom, and blood profile, total protein and fractionated were evaluated. The venom of $\mathrm{T}$. fasciolatus at a dose of $24 \mu \mathrm{g}$ caused piloerection, behavior pain, nasal and oral sharp, dyspnea, rash on the face and exaggerated reflexes. In blood profile were observed relative polycythemia, leukocytosis with lymphocytosis.
\end{abstract}

Keywords: scorpion, Tityus fasciolatus, blood profile, clinical alterations, mice

\section{INTRODUÇÃO}

No Brasil, segundo dados do Ministério da Saúde, ocorreram 10.000 acidentes escorpiônicos em humanos no ano de 1998, com taxa total de mortalidade de $1,1 \%$, porém, quando computada a taxa de mortalidade infantil, essa ultrapassou

Recebido em 15 de novembro de 2010

Aceito em 2 de agosto de 2011

*Autor para correspondência (corresponding author)

E-mail: mariliamm@ufmg.br
$10 \%$. No ano de 2001 , o número de acidentes passou para 18.000 casos, e em 2006 dobrou-se o número de notificações, atingindo 36.000 pessoas. O gênero Tityus é o mais prevalente, e as espécies T. serrulatus e T. bahiensis são as responsáveis pelo maior número de acidentes (Soares et al., 2002; Lourenço e Eicksted, 2003; Pardal et al., 2003; Wagner et al., 2003). Entretanto, no Brasil central (Distrito Federal e 
estado de Goiás) e no Triângulo Mineiro, as espécies mais prevalentes são $T$. serrulatus e $T$. fasciolatus (Lourenço, 2003; Pardal et al., 2003). A espécie $T$. fasciolatus apresenta ocorrência significativa nas referidas regiões, entretanto até o momento não havia dados científicos acerca do envenenamento.

O envenenamento por escorpião pode levar a um complexo conjunto de sinais clínicos. O primeiro deles é a dor local que, nos envenenamentos mais graves, pode não ser observada devido às manifestações sistêmicas (Dias et al., 2001). Os efeitos fisio-farmacológicos induzidos pelas toxinas escorpiônicas são devido à ação específica nos canais de sódio, seguido da despolarização da membrana das células excitáveis e posterior liberação de catecolaminas e acetilcolina pelas terminações nervosas dos sistemas simpático e parassimpático e zona medular adrenal. Dessa forma, as toxinas agem em diferentes sítios do organismo, levando ao aparecimento do quadro clínico. O agravamento dessas alterações pode levar à insuficiência cardiocirculatória, edema pulmonar agudo, choque e morte (Cupo e Hering, 2002), o que revela a importância de se avaliar o quadro clínico apresentado pelo indivíduo envenenado.

O veneno escorpiônico é de natureza complexa e atua de modo sistêmico no organismo. A avaliação hematológica faz parte do perfil traçado em pacientes acidentados e auxilia na determinação de alterações importantes como leucocitose por liberação de hormônios, ação de mediadores farmacológicos nas células sanguíneas, alterações no hematócrito redução de volume circulante, entre outras. Apesar de o envenenamento causado pelo $T$. serrulatus ser bastante estudado, principalmente em função da grande frequência de acidentes e de sua alta letalidade, o envenenamento causado pelo $T$. fasciolatus é pouquíssimo estudado. Diante deste contexto, objetivou-se elucidar o quadro clínico e hematológico de camundongos após envenenamento pelo escorpião T. fasciolatus.

\section{MATERIAL E MÉTODOS}

Os venenos foram extraídos de exemplares das espécies Tityus fasciolatus e Tityus serrulatus capturados na região de Ituiutaba (MG), cedidos pelo Centro de Zoonoses de Ituiutaba (CCZ). O método de extração foi manual, com compressão do télson em papel parafilme, perfuração deste pelo aguilhão e liberação das gotículas do veneno na superfície do papel. As gotículas foram recolhidas para a formação do pool dos respectivos venenos que, em seguida, foram liofilizados. Os venenos liofilizados foram ressuspendidos em solução salina tamponada com fosfato (PBS) para a dosagem de proteínas pelo método do reagente Folin-Fenol-Ciocalteau (Lowry et al., 1951). Logo após a solução foi aliquotada e congelada a $-20^{\circ} \mathrm{C}$.

A espécie $T$. serrulatus funcionou como testemunha, sendo o controle positivo na elucidação dos quadros clínico e hematológico de camundongos após envenenamento pelo escorpião T. fasciolatus, objeto de estudo deste trabalho.

Cinquenta e quatro camundongos Swiss CF1 machos, com peso médio de $30 \mathrm{~g}$, foram distribuídos em três grupos de 18 animais cada. O trabalho foi realizado utilizando esta espécie animal por ser empregada como unidade experimental em ensaios humanos e em medicina veterinária, e em razão do volume de veneno disponível. Os animais do grupo I (GI), inoculados com $50 \mu \mathrm{L}$ de PBS, funcionaram como grupo controle negativo; os animais do grupo II (GII) foram inoculados com $24 \mu \mathrm{g}$ de veneno de Tityus fasciolatus por camundongo, diluído em $50 \mu \mathrm{L}$ de PBS $\left(40 \%\right.$ da DL $_{50}$ conforme Guimarães et al. (2009); e os animais do grupo III (GIII) foram inoculados com $8 \mu \mathrm{g}$ de veneno de Tityus serrulatus por camundongo, diluído em $50 \mu \mathrm{L}$ de PBS $\left(40 \%\right.$ da $\mathrm{DL}_{50}$ do veneno de Tityus serrulatus conforme Nishikawa et al. (1994), funcionando como controle positivo. Cada grupo (GI, GII e GIII) foi dividido em três subgrupos de seis animais, de acordo com o momento da coleta de sangue. O local de inoculação do veneno nos camundongos foi a região interescapular, pela via subcutânea, utilizando-se seringa hipodérmica descartável de 1,0mL(BD Plastipak®).

Foram coletadas amostras de sangue no plexo orbital (cerca de $1,3 \mathrm{~mL}$ de sangue por animal) às uma, oito e 24 horas após a administração do veneno (T1, T8 e $\mathrm{T} 24$, respectivamente). O sangue foi colocado em tubos (VACUETTE®, Greiner Bio-One Brasil - Americana, SP) com sal dissódico do ácido etilenodiaminotetracético (EDTA) a 10\%, para realização do hemograma. 
A contagem total de eritrócitos e leucócitos e a determinação da concentração de hemoglobina foram realizadas em contador eletrônico (CELM CC-530®, Cia. Equipadora de Laboratórios Modernos - Barueri-SP). O volume globular foi determinado utilizando-se tubos para microhematócrito, e foram calculados os índices hematimétricos conforme Thrall, (2004). Os esfregaços sanguíneos foram feitos em lâminas de vidro $(26$ x 76mm) (Lâminas para Microscopia Exacta - Perfecta, São Paulo-SP) e corados com May Grunwald-Giemsa (May Grunwald/Giemsa - Doles ® Reagentes, Goiânia, GO) para a contagem diferencial de leucócitos (Thrall, 2004).

O sangue foi centrifugado para produção de plasma, o qual foi utilizado para determinação da proteína total por refratometria e fracionada por eletroforese. Utilizaram-se tampão Tris e filmes de agarose (CELMGEL ® - CELM - Cia. Equipadora de Laboratórios Modernos, BarueriSP), coloração com amido negro, e as bandas eletroforéticas foram lidas e quantificadas pelo software SE-250 (Software SE-250) para determinação da concentração de albumina, $\alpha, \beta$ e $\gamma$ globulinas, segundo técnica descrita por Naoum (1990).

O delineamento experimental aplicado foi ao acaso, em esquema de parcelas subdivididas, conforme Sampaio (2007). As parcelas corresponderam aos tratamentos (controle e veneno), e as subparcelas aos tempos de avaliação em horas. Os dados referentes aos diferentes grupos e tempos foram plotados em tabelas e analisados pelo programa de computador SAS (SAS® - Statistical Analysis System - Cary, EUA). Foi realizada a análise de variância e a comparação de médias pelos testes Tukey e SNK.

O projeto de pesquisa foi aprovado pelo CETEA - Comitê de Ética em Experimentação Animal da UFMG.

\section{RESULTADOS E DISCUSSÃO}

Todos os camundongos dos grupos II e III, inoculados com os venenos de $T$. fasciolatus e T. serrulatus, apresentaram piloereção, comportamento nociceptivo (demonstração de incômodo após o toque e busca constante por uma posição mais cômoda), secreção nasal e oral acentuadas, dispneia, prurido na face e reflexos normais exacerbados.

A dor no local picado pelo escorpião é o sinal mais comum, predominante no escorpionismo humano em praticamente $100 \%$ dos acidentes. É progressiva e depende da quantidade de veneno inoculada e da sensibilidade individual do acidentado. Ocorre imediatamente após o acidente. Pode irradiar-se até a raiz do membro atingido, exacerbando-se à palpação. $\mathrm{O}$ local da picada é, às vezes, detectado com dificuldade, podendo-se encontrar hiperemia e edema discretos (Cupo e Hering, 2002; Soares et al., 2002; Cupo et al., 2003; Campolina, 2006). Neste experimento foi observado, nos camundongos inoculados com os venenos de $T$. fasciolatus e $T$. serrulatus, comportamento nociceptivo (indicativo de dor).

Uma investigação farmacológica da resposta nociceptiva e da indução de edema pelo veneno de $T$. serrulatus em ratos e camundongos, conduzida por Nascimento Júnior et al. (2005), mostrou como determinadas concentrações de veneno induzem efeitos diferentes. Embora os resultados sejam limitados quanto ao estabelecimento de paralelos entre a experiência de dor humana e a manifestação de dor em animais experimentais, os autores concluíram que o veneno de $T$. serrulatus causou alodinia térmica e mecânica ipsilateral após injeção intraplantar, qualitativamente diferente da experiência humana, que registra alodinia de larga distribuição, alcançando órgãos distantes do local da picada. O comportamento nociceptivo dos animais foi manifestado por incômodo no local onde foi aplicado o veneno, demarcadamente nos primeiros 15 minutos, enquanto o prurido facial instalou-se rapidamente e permaneceu por uma hora. Há suspeitas de que a resposta nociceptiva imediata tenha sido influenciada pela atuação das neurotoxinas e de eicosanoides endógenos sobre fibras aferentes nociceptivas primárias. Tratamentos com drogas antagonistas de aminas biogênicas, tais como histamina e 5hidroxitriptamina (5-HT ou serotonina), que foram identificadas como constituintes do veneno, mas também têm origem endógena, inibiram as respostas nociceptivas e o edema, fazendo-se supor uma ampla participação desses mediadores nesses processos. 
Ribeiro et al. (2010), ao estudarem o envenenamento experimental por $T$. serrulatus em cães, relataram que os animais apresentaram dor local imediata e intensa, seguida de hiperestesia, alterações posturais e claudicação. Embora não se conheça a composição do veneno de $T$. fasciolatus, provavelmente a inoculação deste no tecido subcutâneo dos camundongos resultou em liberação de mediadores farmacológicos da dor, semelhante ao que ocorre após a inoculação do veneno de $T$. serrulatus.

Em humanos, as manifestações respiratórias incluem rinorreia, tosse, espirros, estertores pulmonares, sibilos, taquipneia, dispneia $\mathrm{e}$ bradipneia, mas sem dúvida o edema pulmonar é o sinal mais grave e importante do acidente escorpiônico (Cupo et al., 2003). Em cães também foram observados espirros, rinorreia e dispneia (Ribeiro et al., 2009). Todos os animais dos grupos II e III, após a inoculação do veneno de $T$. fasciolatus e $T$. serrulatus, apresentaram prurido facial e acentuada rinorreia.

O prurido facial apresentado pelos camundongos pode ter sido decorrente de reações de hipersensibilidade do tipo I, provocadas por histamina, anticorpos do tipo IgE, mastócitos, basófilos e eosinófilos. A combinação de $\operatorname{IgE}$ com antígeno na superfície de mastócitos causa a formação de moléculas vasoativas e a liberação de histamina dos grânulos dos mastócitos. A histamina provoca contração da musculatura lisa nos brônquios, trato gastrintestinal e bexiga e aumenta a permeabilidade vascular, causando extravasamento de fluido, além de ser uma potente estimuladora das secreções exócrinas, estimulando a secreção de muco brônquico, lacrimejamento e salivação (Tizard, 2002). A constrição brônquica e a secreção de muco são também consequências da estimulação de receptores muscarínicos pela acetilcolina (Rang et al., 2004), um dos neurotransmissores que podem ser liberados em função da ação neurotóxica do veneno de escorpião.

Revelo et al. (1996) relataram que o veneno de $T$. serrulatus alcança níveis máximos de distribuição nos pulmões de ratos em 30 minutos.
Essa característica farmacocinética coincide com a forma aguda como os sinais foram observados nos camundongos deste experimento. Não foram encontrados, na literatura consultada, relatos de toxinas de veneno escorpiônico que lesem ou irritem a mucosa do trato respiratório superior, mas, diante desses sinais apresentados, tal possibilidade deve ser considerada.

O quadro clínico do envenenamento escorpiônico está na dependência de fatores relacionados com o escorpião e com a vítima. Os fatores relacionados ao escorpião são: espécie, condição do télson no momento do acidente, número de picadas ou quantidade de veneno injetada. Em relação à vítima, há: idade, peso corporal, estado de saúde, doenças concomitantes e ineficácia do tratamento (Dehesa-Dávila e Possani, 1994). Assim, a realização dos exames laboratoriais é essencial, objetivando-se a monitoração do paciente e a reversão do quadro clínico de envenenamento escorpiônico.

As características hematológicas em camundongos podem ser influenciadas por vários fatores, como linhagem, idade, sexo, espécie, anestesia utilizada na coleta, método de contenção e estresse (Thrall, 2004). Com o objetivo de minimizar estes fatores, neste experimento foram escolhidos camundongos machos da mesma linhagem (Swiss), da mesma idade e com mesmo peso. Todos eram procedentes do mesmo biotério, criados nas mesmas condições de manejo e recebendo a mesma alimentação. No momento da coleta de sangue, todos receberam a mesma contenção, conseguindo-se, assim, a padronização dos valores hematológicos.

Em relação ao número dos eritrócitos (Tab. 1), não foi observada diferença significativa entre grupos e tempos $(\mathrm{P}>0,05)$. Houve um aumento $(\mathrm{P}<0,05)$ da concentração de hemoglobina (Tab. 2) e do volume globular (Tab. 3) no grupo II, oito horas após a inoculação do veneno de $T$. fasciolatus, quando comparado com outros grupos. 


\section{Guimarães et al.}

Tabela 1. Valores médios do número de eritrócitos (x $\left.10^{6} / \mu \mathrm{L}\right)$ de camundongos inoculados com PBS (grupo I), veneno de Tityus fasciolatus (grupo II) e Tityus serrulatus (grupo III) em diferentes tempos

\begin{tabular}{lccc} 
& \multicolumn{3}{c}{ Eritrócitos $\left(\mathrm{x} 10^{6} / \mu \mathrm{L}\right)$} \\
\cline { 2 - 4 } Tempo & Grupo I & Grupo II & Grupo III \\
\hline T1h & 8,60 & 8,81 & 8,86 \\
T8h & 8,41 & 9,01 & 8,44 \\
T24h & 8,48 & 8,47 & 8,52 \\
\hline
\end{tabular}

Não houve diferença significativa $(\mathrm{P}>0,05)$ após análise de variância e teste SNK.

O discreto aumento do número dos eritrócitos e os significativos aumentos da concentração de hemoglobina e do volume globular podem ter sido decorrentes da dor e do estresse (efeito das catecolaminas), levando a uma contração esplênica, fato este relatado por Tarasiuk e Sofer (1999), quando estudaram o envenenamento escorpiônico em cães. Outros autores também relataram policitemia relativa após envenenamento causado por $T$. serrulatus em cães (Ribeiro et al., 2009) e ratos (Pinto et al., 2010).

Como os animais manifestaram abundante salivação e rinorreia, que poderiam levar a um quadro de desidratação, essa também pode ter sido responsável pela discreta hemoconcentração, pois os valores da proteína total também apresentaram discreto aumento. De forma semelhante, Bertazzi et al. (2003) relataram hemoconcentração, em ratos, após a inoculação de veneno bruto de $T$. serrulatus e de sua toxina mais importante, a TsTX-I, e atribuíram sua ocorrência às perdas de líquidos por salivação, lacrimejamento e micção. Andrade et al. (2004) realizaram uma avaliação dos níveis plasmáticos de eletrólitos e do balanço acidobásico em ratos e observaram aumento significativo do volume globular 60 minutos após a inoculação de veneno de $T$. serrulatus. Cusinato et al. (2010) observaram aumento significativo de volume globular e hemoglobina em ratos após inoculação do veneno de $T$. serrulatus e afirmaram que a hemoconcentração foi decorrente de desidratação.

Tabela 2. Valores médios das concentrações de hemoglobina $(\mathrm{g} / \mathrm{dL})$ de camundongos inoculados com PBS (grupo I), veneno de Tityus fasciolatus (grupo II) e Tityus serrulatus (grupo III) em diferentes tempos

\begin{tabular}{lccc}
\hline Tempo & \multicolumn{3}{c}{ Hemoglobina $(\mathrm{g} / \mathrm{dL})$} \\
\cline { 2 - 4 } & Grupo I & Grupo II & Grupo III \\
\hline T1h & $14,18 \mathrm{Aa}$ & $13,71 \mathrm{Aab}$ & $13,83 \mathrm{Aa}$ \\
T8h & $13,33 \mathrm{Ba}$ & $14,43 \mathrm{Aa}$ & $13,42 \mathrm{Ba}$ \\
T24h & $13,62 \mathrm{Aa}$ & $13,57 \mathrm{Ab}$ & $13,45 \mathrm{Aa}$ \\
\hline
\end{tabular}

Médias seguidas de letras maiúsculas distintas diferem estatisticamente entre os grupos (linha), e seguidas de letras minúsculas distintas diferem estatisticamente entre os tempos (coluna), pelo teste $\mathrm{SNK}(\mathrm{P}<0,05)$.

Tabela 3. Valores médios do volume globular (\%) de camundongos inoculados com PBS (grupo I), veneno de Tityus fasciolatus (grupo II) e Tityus serrulatus (grupo III) em diferentes tempos

\begin{tabular}{lccc} 
Tempo & \multicolumn{3}{c}{ Volume globular (\%) } \\
\cline { 2 - 4 } & Grupo I & Grupo II & Grupo III \\
\hline T1 & $42,33 \mathrm{Aa}$ & $42,67 \mathrm{Ab}$ & $44,67 \mathrm{Aa}$ \\
T8 & $41,67 \mathrm{Ba}$ & $45,67 \mathrm{Aa}$ & $42,67 \mathrm{Bab}$ \\
T24 & $39,67 \mathrm{Aa}$ & $41,0 \mathrm{Ab}$ & $41,50 \mathrm{Ab}$ \\
\hline
\end{tabular}

Médias seguidas de letras maiúsculas distintas diferem entre os grupos (linha), e seguidas de letras minúsculas distintas diferem entre os tempos (coluna), pelo teste SNK $(\mathrm{P}<0,05)$. 
Não houve diferença entre os valores de volume globular médio (VGM), hemoglobina globular média (HGM) e concentração de hemoglobina globular média (Tab. 4). O veneno de escorpiões não é caracterizado na literatura científica como causador de anemia, hemólise, lesões vasculares ou interferências na medula óssea, de modo que a manutenção da contagem de hemácias, da concentração de hemoglobina e do volume globular médio é coerente com esse fato.

Tabela 4. Valores médios de hemoglobina globular média, HGM (pg), volume globular médio, VGM (g/dL) e concentração de hemoglobina globular média, CHGM (fL) de camundongos inoculados com PBS (grupo I), veneno de Tityus fasciolatus (grupo II) e Tityus serrulatus (grupo III) em diferentes tempos

\begin{tabular}{lccccccccc}
\hline Tempo & \multicolumn{3}{c}{ HGM (pg) } & \multicolumn{3}{c}{ VGM (g/dL) } & \multicolumn{3}{c}{ CHGM (fL) } \\
\hline & Grupo I & Grupo II & Grupo & Grupo I & Grupo II & Grupo & Grupo I & Grupo II & Grupo \\
& & & III & & & III & & & III \\
\hline T1h & $16,33 \mathrm{Aa}$ & $15,55 \mathrm{Aa}$ & $15,67 \mathrm{Aa}$ & $48,83 \mathrm{Aa}$ & $48,52 \mathrm{Aa}$ & $50,60 \mathrm{Aa}$ & $33,52 \mathrm{Aab}$ & $32,18 \mathrm{Aba}$ & $31,02 \mathrm{Ba}$ \\
T8h & $15,95 \mathrm{Aa}$ & $16,05 \mathrm{Aa}$ & $15,85 \mathrm{Aa}$ & $49,72 \mathrm{Aa}$ & $50,75 \mathrm{Aa}$ & $50,45 \mathrm{Aa}$ & $32,18 \mathrm{Ab}$ & $31,67 \mathrm{Aa}$ & $31,43 \mathrm{Aa}$ \\
T24h & $16,07 \mathrm{Aa}$ & $16,05 \mathrm{Aa}$ & $15,85 \mathrm{Aa}$ & $46,82 \mathrm{Aa}$ & $48,60 \mathrm{Aa}$ & $48,87 \mathrm{Aa}$ & $34,32 \mathrm{Aa}$ & $33,08 \mathrm{Aba}$ & $32,42 \mathrm{Ba}$ \\
\hline
\end{tabular}

Médias seguidas de letras maiúsculas distintas diferem entre os grupos (linha), e seguidas de letras minúsculas distintas diferem entre os tempos (coluna), pelo teste SNK $(\mathrm{P}<0,05)$.

Observou-se aumento $(\mathrm{P}<0,05)$ da contagem total dos leucócitos no GII (T. fasciolatus) oito horas após a inoculação do veneno (Tab. 5), ultrapassando de forma discreta os limites máximos para a espécie $(2,61$ a 10,05) (Thrall,
2004). Leucocitose também foi observada por Ribeiro et al. (2009) em cães, e por Pinto et al. (2010) em ratos envenenados com o veneno de T. serrulatus, retornado à normalidade após 24 horas.

Tabela 5. Valores médios do número total de leucócitos $\left(\mathrm{x} 10^{3} / \mu \mathrm{L}\right)$ de camundongos inoculados com PBS (grupo I), veneno de Tityus fasciolatus (grupo II) e Tityus serrulatus (grupo III) em diferentes tempos

\begin{tabular}{lccc}
\hline Tempo & \multicolumn{2}{c}{ Leucócitos totais $\left(\mathrm{x} 10^{3} / \mu \mathrm{L}\right)$} & \\
\cline { 2 - 4 } & Grupo I & Grupo II & Grupo III \\
\hline T1h & $7,18 \mathrm{Aa}$ & $6,45 \mathrm{Ab}$ & $7,08 \mathrm{Aab}$ \\
T8h & $9,37 \mathrm{Aab}$ & $10,18 \mathrm{Aa}$ & $7,48 \mathrm{Bb}$ \\
T24h & $8,25 \mathrm{Aa}$ & $7,22 \mathrm{Ab}$ & $8,37 \mathrm{Aa}$ \\
\hline
\end{tabular}

Médias seguidas de letras maiúsculas distintas diferem entre os grupos (linha), e seguidas de letras minúsculas distintas diferem entre os tempos (coluna), pelo teste SNK $(\mathrm{P}<0,05)$.

Leucocitose com neutrofilia é uma alteração comum, registrada em muitos casos clínicos humanos de envenenamento escorpiônico (Bucaretchi et al., 1995; Cupo e Hering, 2002) e também em cães (Ribeiro et al., 2009). Embora sejam relatadas reações inflamatórias decorrentes das neurotoxinas presentes no veneno dos escorpiões, como miocardite e pancreatite, e a vasta participação de citocinas e mediadores inflamatórios (óxido nítrico, leucotrienos, catecolaminas, bradicininas e prostaglandinas), conforme descrito por Fukuhara et al. (2003 e 2004), o mecanismo mais provável é o estresse causado pela dor, que maximiza a descarga de adrenalina e provoca leucocitose fisiológica devido ao desprendimento de leucócitos do pool marginal dos vasos sanguíneos (Jain, 1993).
Não houve alteração do número absoluto de neutrófilos entre grupos ou tempos (Tab. 6). Em relação ao número de linfócitos, pode-se observar um aumento $(\mathrm{P}<0,05)$ nos animais do GII (T. fasciolatus) oito horas após a inoculação do veneno. Os linfócitos são as principais células circulantes dos camundongos. Portanto, a leucocitose fisiológica descrita anteriormente provavelmente foi decorrente da linfocitose.

Em relação ao número absoluto de monócitos e eosinófilos, não houve diferença entre os grupos estudados (Tab. 7).

Neste experimento, observou-se um aumento significativo $(\mathrm{P}<0,05)$ das proteínas plasmáticas após oito e 24 horas no GII (Tab. 8). No GIII, os valores de proteínas totais foram maiores no T8, quando comparado com T1 e T24. 


\section{Guimarães et al.}

Tabela 6. Valores médios absolutos de neutrófilos e linfócitos (x $\left.10^{3} / \mu \mathrm{L}\right)$ de camundongos inoculados com PBS (grupo I), veneno de Tityus fasciolatus (grupo II) e Tityus serrulatus (grupo III) em diferentes tempos

\begin{tabular}{lrrrrrc}
\hline Tempo & \multicolumn{3}{c}{ Neutrófilos $\left(\times 10^{3} / \mu \mathrm{L}\right)$} & \multicolumn{3}{c}{ Linfócitos $\left(\times 10^{3} / \mu \mathrm{L}\right)$} \\
\hline & Grupo I & Grupo II & Grupo III & Grupo I & Grupo II & Grupo III \\
\hline T1h & $0,95 \mathrm{Aa}$ & $1,04 \mathrm{Aa}$ & $1,33 \mathrm{Aa}$ & $5,84 \mathrm{Aa}$ & $5,10 \mathrm{Ab}$ & $5,50 \mathrm{Aa}$ \\
T8h & $0,82 \mathrm{Aa}$ & $1,10 \mathrm{Aa}$ & $1,45 \mathrm{Aa}$ & $7,89 \mathrm{Aa}$ & $8,50 \mathrm{Aa}$ & $5,60 \mathrm{Ba}$ \\
T24h & $0,97 \mathrm{Aa}$ & $0,86 \mathrm{Aa}$ & $1,30 \mathrm{Aa}$ & $6,60 \mathrm{Aa}$ & $5,97 \mathrm{Ab}$ & $6,53 \mathrm{Aa}$ \\
\hline
\end{tabular}

Médias seguidas de letras maiúsculas distintas diferem entre os grupos (linha), e seguidas de letras minúsculas distintas diferem entre os tempos (coluna), pelo teste SNK $(\mathrm{P}<0,05)$.

Tabela 7. Valores médios absolutos de monócitos e eosinófilos (x 10\% $/ \mu \mathrm{L}$ ) de camundongos inoculados com PBS (grupo I), veneno de Tityus fasciolatus (grupo II) e Tityus serrulatus (grupo III) em diferentes tempos

\begin{tabular}{lcccccc}
\hline Tempo & \multicolumn{3}{c}{ Monócitos $\left(\times 10^{3} / \mu \mathrm{L}\right)$} & \multicolumn{3}{c}{ Eosinófilos $\left(\times 10^{3} / \mu \mathrm{L}\right)$} \\
\hline & Grupo I & Grupo II & Grupo III & Grupo I & Grupo II & Grupo III \\
\hline T1h & 0,29Ab & $0,23 \mathrm{Aa}$ & $0,19 \mathrm{Aa}$ & $0,10 \mathrm{Ab}$ & $0,10 \mathrm{Ab}$ & $0,07 \mathrm{Aa}$ \\
T8h & $0,35 \mathrm{Aab}$ & $0,27 \mathrm{Aa}$ & $0,30 \mathrm{Aa}$ & $0,29 \mathrm{Aa}$ & $0,30 \mathrm{Aa}$ & $0,12 \mathrm{Aa}$ \\
T24h & $0,52 \mathrm{Aa}$ & $0,32 \mathrm{Aa}$ & $0,34 \mathrm{Aa}$ & $0,15 \mathrm{Ab}$ & $0,07 \mathrm{Ab}$ & $0,19 \mathrm{Aa}$ \\
\hline
\end{tabular}

Médias seguidas de letras maiúsculas distintas diferem entre os grupos (linha), e seguidas de letras minúsculas distintas diferem entre os tempos (coluna), pelo teste SNK $(\mathrm{P}<0,05)$.

Tabela 8. Valores médios das concentrações de proteínas plasmáticas (g/L) de camundongos inoculados com PBS (grupo I), veneno de Tityus fasciolatus (grupo II) e Tityus serrulatus (grupo III) em diferentes tempos

\begin{tabular}{lccc}
\hline Tempo & \multicolumn{3}{c}{ Proteínas plasmáticas $(\mathrm{g} / \mathrm{L})$} \\
\cline { 2 - 4 } & Grupo I & Grupo II & Grupo III \\
\hline T1h & $5,60 \mathrm{Ab}$ & $5,33 \mathrm{ABb}$ & $5,10 \mathrm{Bb}$ \\
T8h & $5,80 \mathrm{ABb}$ & $6,10 \mathrm{Aa}$ & $5,50 \mathrm{Ba}$ \\
T24h & $6,17 \mathrm{Aa}$ & $6,27 \mathrm{Aa}$ & $5,13 \mathrm{Bb}$ \\
\hline
\end{tabular}

Médias seguidas de letras maiúsculas distintas diferem entre os grupos (linha), e seguidas de letras minúsculas distintas diferem entre os tempos (coluna), pelo teste SNK $(\mathrm{P}<0,05)$.

Em relação à albumina, ocorreu um aumento $(\mathrm{P}<0,05)$ no GI (PBS) e uma diminuição no GIII (veneno T. serrulatus) $24 \mathrm{~h}$ após a inoculação (Tab.9). A albumina é a mais abundante das proteínas, correspondendo a quase $50 \%$ do total proteico. É importante na regulação e manutenção da pressão osmótica do sangue, além de atuar no transporte de compostos proteicos e na solubilização de substâncias (Kaneko, 1997).

O perfil eletroforético pode sugerir a ocorrência de processos inflamatórios agudos e crônicos, disfunções hepáticas, perdas proteicas, síndromes nefróticas e alterações das globulinas que ajudam o entendimento da resposta imunológica (Naoum, 1990).

Tabela 9. Valores médios de albumina (g/dL) de camundongos inoculados com PBS (grupo I), veneno de Tityus fasciolatus (grupo II) e Tityus serrulatus (grupo III) em diferentes tempos

\begin{tabular}{lccc} 
Tempo & \multicolumn{3}{c}{ Albumina (g/dl) } \\
\cline { 2 - 4 } & Grupo I & Grupo II & Grupo III \\
\hline T1h & $3,48 \mathrm{Ab}$ & $3,53 \mathrm{Aa}$ & $3,21 \mathrm{Aa}$ \\
T8h & $3,65 \mathrm{Aab}$ & $3,67 \mathrm{Aa}$ & $3,55 \mathrm{Aa}$ \\
T24h & $4,07 \mathrm{Aa}$ & $3,74 \mathrm{Aa}$ & $3,12 \mathrm{Ba}$ \\
\hline
\end{tabular}

Médias seguidas de letras maiúsculas distintas diferem entre os grupos (linha), e seguidas de letras minúsculas distintas diferem entre os tempos (coluna), pelo teste SNK $(\mathrm{P}<0,05)$. 
Não foi observada diferença significativa entre os tempos dentro de cada grupo na fração $\alpha$-globulina (Tab.10). Mas, quando se comparam os grupos, o GII (T. fasciolatus) $24 \mathrm{~h}$ após a inoculação do veneno, apresentou os maiores valores $(\mathrm{P}<0,05)$. $\mathrm{O}$ grupo das $\alpha$-globulinas é composto por $\alpha$-1-glicoproteínaácida, $\alpha$-antiquimotripsina; $\alpha$-2-macroglobulina, naturalmente elevada em jovens e idosos; $\alpha$-1-antitripsina, a mais importante delas e responsável por neutralizar enzimas proteolíticas bacterianas ou leucocitárias da inflamação; e a haptoglobina, que representa a principal proteína de fase aguda nos processos inflamatórios (Kaneko, 1997).

Também houve aumento das $\beta$-globulinas em T8 e em T24 no GII ( $T$. fasciolatus). Nos casos de injúrias teciduais sistêmicas por agentes externos, há liberação de citocinas. As interleucinas 1,6 e o TNF- $\alpha$, presentes na resposta inflamatória frente ao envenenamento, estimulam a síntese hepática de proteínas, especialmente as de fase aguda, sendo esta resposta iniciada em poucas horas. Este mecanismo poderia justificar o aumento das $\beta$-globulinas.

Em relação às $\gamma$-globulinas, somente foi observada diferença significativa oito horas após a inoculação do veneno entre os grupos I e III (Tab. 10). O aumento da fração $\gamma$-globulínica representa resposta frente à estimulação antigênica evocada pelo veneno.

Tabela 10. Valores médios das $\alpha, \beta$ e $\gamma$-globulinas (g/dL) de camundongos inoculados com PBS (grupo I), veneno de Tityus fasciolatus (grupo II) e Tityus serrulatus (grupo III) em diferentes tempos

\begin{tabular}{lccccccccc}
\multirow{2}{*}{ Tempo } & \multicolumn{2}{c}{$\alpha$-globulinas (g/dL) } & \multicolumn{3}{c}{$\beta$-globulinas (g/dL) } & \multicolumn{2}{c}{$\gamma$-globulinas (g/dL) } \\
\cline { 2 - 10 } & Grupo I & Grupo II & Grupo III & Grupo I & Grupo II & Grupo III & Grupo I & Grupo II & Grupo III \\
\hline T1h & $0,74 \mathrm{Aab}$ & $0,72 \mathrm{Aa}$ & $0,65 \mathrm{Aa}$ & $1,35 \mathrm{Ab}$ & $1,05 \mathrm{Ab}$ & $1,21 \mathrm{Aa}$ & $0,03 \mathrm{Aa}$ & $0,03 \mathrm{Aa}$ & $0,02 \mathrm{Aa}$ \\
T8h & $0,85 \mathrm{Aa}$ & $0,87 \mathrm{Aa}$ & $0,81 \mathrm{Aa}$ & $1,28 \mathrm{Ab}$ & $1,53 \mathrm{Aa}$ & $1,22 \mathrm{Aa}$ & $0,02 \mathrm{Ba}$ & $0,03 \mathrm{ABa}$ & $0,04 \mathrm{Aa}$ \\
T24h & $0,66 \mathrm{Bb}$ & $0,87 \mathrm{Aa}$ & $0,81 \mathrm{ABa}$ & $1,90 \mathrm{Aa}$ & $1,78 \mathrm{Aa}$ & $1,17 \mathrm{Ba}$ & $0,03 \mathrm{Aa}$ & $0,03 \mathrm{Aa}$ & $0,03 \mathrm{Aa}$ \\
\hline
\end{tabular}

Médias seguidas de letras maiúsculas distintas diferem entre os grupos (linha), e seguidas de letras minúsculas distintas diferem entre os tempos (coluna), pelo teste SNK $(\mathrm{P}<0,05)$.

\section{CONCLUSÕES}

O veneno de $T$. fasciolatus foi capaz de causar alterações em camundongos semelhantes às descritas no envenenamento por $T$. serrulatus, incluindo piloereção, comportamento nociceptivo, secreção nasal e oral acentuada, dispneia, prurido na face, bem como reflexos exacerbados e alterações hematológicas, tais como policitemia, leucocitose com linfocitose e aumento das alfa e betaglobulinas.

\section{REFERÊNCIAS BIBLIOGRÁFICAS}

ANDRADE, M.V.; CARAMEZ, M.P.; ABREU, E.M.N.N. et al. Lung compliance, plasma electrolyte levels and acid-base balance are affected by scorpion envenomation in anesthetized rats under mechanical ventilation. Comp. Biochem. Physiol., Part C, v.138, p.97-104, 2004.

BERTAZZI, D.T.; ASSIS-PANDOCHI, A.I.; SEIXAS, A.E.C. et al. Effects of Tityus serrulatus scorpion venom and its major toxin, TsTX-I, on the complement system in vivo. Toxicon, v.41, p. 501508, 2003.
BUCARETCHI, F.; BARACAT, C.E.; NOGUEIRA, R.J.N. A comparative study of severe scorpion envenomation in children caused by Tityus bahiensis and Tityus serrulatus. Rev. Inst. Med. Trop. Sao Paulo, v.37, p.331-336, 1995.

CAMPOLINA, D. Georreferencimento e estudo clínico-epidemiológico dos acidentes escorpiônicos atendidos em Belo Horizonte, no serviço de toxicologia de Minas Gerais. 2006. $127 \mathrm{f}$. Dissertação (Mestrado em Ciências da Saúde) Faculdade de Medicina, Universidade Federal de Minas Gerais, Belo Horizonte, MG.

CUPO, P.; AZEVEDO-MARQUES, M.M.; HERING, S.E. Escorpiões de importância médica. In: CARDOSO, J.L.C.; FRANÇA, F.O.S.; FAN, H.W. et al. Animais peçonhentos no Brasil: biologia clínica e terapêutica dos acidentes. São Paulo: Salvier, 2003. p.198-208.

CUPO, P.; HERING, S.E. Cardiac troponin I release after severe scorpion envenoming by Tityus serrulatus. Toxicon, v.40, p.823-830, 2002. 
CUSINATO, D.A.C.; SOUZA, A.M.; VASCONCELOS, F. et al. Assessment of biochemical and hematological parameters in rats injected with Tityus serrulatus scorpion venom. Toxicon, v.67, p.2588-2597, 2010.

DEHESA-DÁVILA, M.; POSSANI, L.D. Scorpionism and serotherapy in Mexico. Toxicon, v.32, p.1015-1018, 1994.

DIAS, M.B.; CAMPOLINA, D.; GUERRA, S.D. et al. Escorpionismo In: FILHO, A.A. Toxicologia na prática clínica. Belo Horizonte: Folium, 2001. p.155165.

FUKUHARA, Y.D.M.; DELLALIBERAJOVILIANO, R.; CUNHA, F.Q.C. et al. The kinin system in the envenomation caused by the Tityus serrulatus scorpion sting. Toxicol. Appl. Pharmacol., v.196, p.390-395, 2004.

FUKUHARA, Y.D.M.; REIS, M.L.; DELLALIBERA-JOVILIANO, R. et al. Increased plasma levels of IL-1 $\beta$, IL- 6 , IL- 8 , IL-10, and TNF- $\alpha$ in patients moderately or severely envenomed by Tityus serrulatus scorpion sting. Toxicon, v. 41, p.4955, 2003.

GUIMARÃES, P.T.; PINTO, M.C.L., LABARRÈRE, C.R. et al. Alterações bioquímicas e anátomohistopatológicas causadas pelo veneno do escorpião Tityus fasciolatus em camundongos, Rev. Bras. Cien. Vet., v.16, p.51-57, 2009.

JAIN, N. C. Essentials of veterinary hematology. Philadelphia: Lea \& Febiger, 1993. 417p.

KANEKO, J.J. Serum proteins and the dysproteinemias. In: KANEKO, J.J.; HARVEY, J. W.; BRUSS, M.L. Clinical biochemistry of domestic animals. 5.ed. San Diego:Academic, 1997. p.117-138.

LOURENÇO, W.R. Description of a new species of Tityus (Scorpiones, Buthidae) from Serra do Cipó in the State of Minas Gerais, Brazil. Rev. Suisse Zool., v.110, p.427-435, 2003.

LOURENÇO, W.R.; EICKSTEDT, V.R.D. Escorpiões de importância médica. In: CARDOSO, J.L.C.; FRANÇA, F.O.S.; FAN, H.W. et al. Animais peçonhentos no Brasil biologia clínica e terapêutica dos acidentes. São Paulo: Salvier, 2003. p. 182-197.

LOWRY, O.H.; ROSEBROUGH, N.J.; FARR, A.L. et al. Protein measurement with folin phenol reagent. $J$. Biol. Chem., v.193, p.265-275, 1951.

NAOUM, P.C. Eletroforese: técnicas e diagnósticos. São Paulo: Livraria Santos, 1990. 174p.

NASCIMENTO JÚNIOR, E.B.; COSTA, K.A.; BERTOLLO, C.M. et al. Pharmacological investigation of the nociceptive response and edema induced by venom of the scorpion Tityus serrulatus. Toxicon, v.45, p.585-593, 2005.
NISHIKAWA, A.K.; CARICATI, C.P.; LIMA, M.L.; et al. Antigenic cross-reactivity among the venoms from several species of Brazilian scorpions. Toxicon, v.32, p. 989-998, 1994

PARDAL, P.P.O.; CASTRO, L.C.; JENNINGS, E. et al. Aspectos epidemiológicos e clínicos do escorpionismo na região de Santarém, Estado do Pará, Brasil. Rev. Soc. Bras. Med. Trop., v.36, p.349-353, 2003.

PINTO, M.C.L., MELO, M.M., LABARRÉRE, C.R. et al. Hematological and biochemical profiles of rats submitted to experimental poisoning with Tityus serrulatus venom. Arq. Bras. Med. Vet. Zootec., v.62, p. $350-356,2010$.

RANG, H.P.; DALE, M.M.; RITTER, J.M. Farmacologia. 5.ed. Rio de Janeiro: Elsevier, 2004.

REVELO, M.P.; BAMBIRRA, E.A.; FERREIRA, A.P. et al. Body distribution of Tityus serrulatus scorpion venom in mice and effects of scorpion antivenom. Toxicon, v.34, p.1119-1125, 1996.

RIBEIRO, E.L.; MELO, M.M.; PINTO, M.C.L. et al. Hemograma de cães submetidos ao envenenamento experimental por Tityus serrulatus. Arq. Bras. Med. Vet. Zootec., v.61, p.135-143, 2009.

RIBEIRO, E. L.; PINTO, M.C.L.; LABARRÈRE, C.R. et al. Biochemical profile of dogs experimentally envenomed with Tityus serrulatus scorpion venom. Toxicon, v.55, p.1125-1131, 2010.

SAMPAIO, I.B.M. Estatística aplicada à experimentação animal. 3.ed. Belo Horizonte: Fundação de Ensino e Pesquisa em Medicina Veterinária e Zootecnia, 2007. 264p.

SOARES, M.R.M.; AZEVEDO, C.S.; MARIA, M. Escorpionismo em Belo Horizonte, MG: um estudo retrospectivo. Rev. Soc. Bras. Med. Trop., v.35, p.359363,2002

TARASIUK, A.; SOFER, S. Effects of adrenergicreceptor blockade and ligation of spleen vessels on the hemodynamics of dogs injected with scorpion venom. Crit. Care Med., v.25, p.365-372, 1999.

THRALL, M.A. Veterinary hematology and clinical chemistry. Philadelphia: Lippincott Williams \& Wilkins, 2004. 518p.

TIZARD, I.R. Imunologia veterinária: uma introdução. 6.ed. São Paulo: Roca. 2002. 532p.

WAGNER, S.; CASTRO, M.S.; BARBOSA, J.A.R.G. et al. Purification and primary structure determination of Tf4, the first bioactive peptide isolated from the venom of the Brazilian scorpion Tityus fasciolatus. Toxicon, v.41, p.737-745, 2003. 